\title{
Olabilirlik ortalama - varyans modelinin matematiksel analizi
}

\author{
Furkan GÖKTAŞ ${ }^{1}$, Ahmet DURAN²,* \\ ${ }^{1}$ Karabük Üniversitesi Işletme Fakültesi, Demir Çelik kampüsü, Karabük \\ ${ }^{2}$ İstambul Teknik Üniversitesi Fen-Edebiyat Fakültesi, Matematik Mühendisliği Bölümü, \\ Ayază̆a kampüsü, İstanbul \\ Geliş Tarihi (Received Date): 26.07.2019 \\ Kabul Tarihi (Accepted Date): 24.10.2019
}

$\ddot{\mathbf{O z}}$

Olabilirlik ortalama - varyans (OV) modeli, kesin olmayan olasılı̆̆ın modellenebilmesine ve kişisel yarglların ve beklentilerin portföy seçimi problemine entegre edilebilmesine imkan verir. Bu nedenle Markovitz'in geleneksel OV modelinin dikkate değer bir alternatifidir. $\quad B u$ çalışmada varlık getirilerinin olabilirlik dağılımlarının üçgensel bulanık sayılar ile verildiği varsayımı altında bu modelin matematiksel analizi yapılmıştır. Bu kapsamda performansı ya da faydayı maksimum yapan portföyler analitik olarak elde edilmiştir. Ayrıca bu modelin verdiği etkin sınırın yapısı örnekler ile açıklanmıştır.

Anahtar kelimeler: Portföy seçimi, olabilirlik teorisi, üçgensel bulanık sayılar, ortalama - varyans modeli, etkin sinır, lineer programlama.

\section{Mathematical analysis of the possibilistic mean - variance model}

\begin{abstract}
The possibilistic mean - variance (MV) model enables the practitioners to model the imprecise probability and integrate their subjective judgements into the portfolio selection problem. Thus, it is a considerable alternative of the Markowitz's traditional $M V$ model. In this study, we analyze this model mathematically under the assumption that the possibility distributions of asset returns are given with the triangular fuzzy numbers. Within this scope, the portfolios which maximize the utility or performance are derived analytically. Furthermore, we illustrate the structure of its efficient frontier with examples.
\end{abstract}

Furkan GÖKTAŞ, furkangoktas@karabuk.edu.tr, https://orcid.org/0000-0001-9291-3912

*Ahmet DURAN, aduran@itu.edu.tr, https://orcid.org/0000-0001-9835-0006 
Keywords: Portfolio selection, possibility theory, triangular fuzzy numbers, mean variance model, efficient frontier, linear programming.

\section{Giriş}

[1]'de tanitılan Markovitz'in geleneksel OV modeli, portföy yönetimi teorisi üzerinde derin bir etki bırakmıştır [2]. Öte yandan bu model, parametrelerinin tahminindeki istatistiksel hatalardan dolayı uygulamada pek tercih edilmez. Bu problemin çözümünde dayanıklı OV modelleri kullanılabilir [2-5]. Ama bu modeller en kötü durum odaklı olduklarından genellikle tutucu olmayan yatırımcılar için uygun değildir $[5,6]$. Ayrica bu modeller önemli bilgi taşıyabilen daha üst momentleri ihmal ederler $[7,8]$. Kesin olmayan olasilıkla mücadelede [9]'da tanitılan ve tahmin hatasinın etkisini azaltan Bayesyen yaklaşım da kullanılabilir. Bu yaklaşımda örneklem ortalama vektörü, genellikle varyansı minimum yapan portföyün ortalamasına yaklaştırılır. Bu nedenle portföyde risksiz varlığın bulunmadığı durumlarda Bayesyen yaklaşım ve parametrelerin yansız tahmincilerini kullanan Markovitz'in geleneksel yaklaşımı özdeş etkin sinır verir [4].

[10]'da tanıtılan Olabilirlik OV modeli, yukarıda bahsedilen modellerin aksine Olasılık Teorisine değil Olabilirlik Teorisine dayanır ve veri setindeki çarpıklığı dikkate alır. Ayrıca Bayesyen yaklaşım gibi kişisel yargıların ve beklentilerin portföy seçimine entegre edilebilmesine imkan verir $[10,11]$. Bu model varlık getirilerinin olabilirlik dağılımları, dört parametre ile tanımlanan yamuk bulanık sayılarla verildiğinde Sıralı Minimal Optimizasyon (SMO) algoritması ile etkili bir şekilde çözülebilir [12]. Bu olabilirlik dağılımları, üç parametre ile tanımlanan üçgensel bulanık sayılar ile verildiğinde ise bu model lineer programla problemine indirgenir ve Simpleks algoritma ile kolayca çözülür [11]. Buradaki üç parametre ilgili varlığın elde tutma (modelleme) periyodundaki getiri öngörüsü için sırasıyla en kötü duruma, temel duruma ve en iyi duruma karşı gelmektedir. Ayrıca bu model, en kötü durum odaklı olmadığından tutucu olmayan yatırımcılar için de uygundur. Bu nedenlerden ötürü belirsizlik altında portföy seçiminde dikkate değer bir alternatif olarak görülebilir.

Teorideki ve pratikteki önemine karşın, bu olabilirlik dağılımlarının üçgensel bulanık sayılar ile verildiği varsayımı altında olabilirlik OV modelinin matematiksel analizi bildiğimiz kadarıyla yapılmamıştır. Literatürdeki bu boşluğu doldurabilmek amacıyla Bölüm 2'de Olabilirlik Teorisindeki temel kavramlar verildikten sonra Bölüm 3'te bu model, bu varsayım altında teorik olarak incelenmiştir. Bu kapsamda faydayı ya da performans1 maksimum yapan portföyler analitik olarak elde edilmiştir. Bununla birlikte Bölüm 4'te farklı etkin sınır yapıları örnekler ile açıklanmıştır. Bölüm 5'teki değerlendirmeler ile çalışma sonuçlandırılmıştır.

\section{Olabilirlik teorisindeki temel kavramlar}

Olabilirlik Teorisinde olabilirlik, klasik yaklaşımda limit frekansları olarak tanımlanan olasılığın yerini alır. Olabilirlik kavramı, olayların meydana gelme eğilimi ile ilgili olan akla uygunluğu işaret eder. Bu teoride, olasılık ölçüsünden farklı olarak "self-dual" olmayan iki farklı ölçü kullanılır. Burada, olabilirlik ölçüsü bir olayın akla uygunluğunu temsil ederken, gereklilik ölçüsü olayın kesinliğini temsil eder [13]. Bu 
ölçüler olabilirlik dağılımları kullanılarak tanımlanmaktadır. Bu dağılımlar ise geçmiş veriler veya kişisel yargılar ve beklentiler doğrultusunda belirlenebilir ve bu çalışmada olduğu gibi genellikle bulanık sayılarla verilir. $\mathrm{Bu}$ nedenlerden ötürü bu bölümde bulanık sayılar ve Olabilirlik Teorisi hakkındaki temel kavramlar [14, 15]'ten yararlanılarak kısaca verilmiştir.

Tanım 1: $\bar{Y}$ üyelik fonksiyonu $v(y)$ olan bulanık küme olsun. $\bar{Y}$ 'nin $\alpha$-kesmesi, $K$ kapanış operatörü olmak üzere aşağıdaki gibidir. $Q$ ise $\bar{Y}$ 'nin desteğidir.

$Y^{\alpha}=\left\{\begin{array}{c}\{y: v(y) \geq \alpha\}, \alpha>0 \\ Q:=K(\{y: v(y)>\alpha\}), \alpha=0 .\end{array}\right.$

$\bar{Y}$ 'nin sürekli olan aşağıdaki üyelik fonksiyonu $b \leq y \leq c$ aralığında artan ve $d \leq y \leq e$ aralığında azalan fonksiyon olsun. O zaman $\bar{Y}$ bulanık sayıdır. Ayrıca $h(y)$ ve $g(y)$ lineer fonksiyon ve $c=d(c \neq d)$ ise üçgensel (yamuk) bulanık sayı olarak adlandırılır.

$$
v(y)=\left\{\begin{array}{c}
0, y \leq b \\
h(y), y \in[b, c] \\
1, y \in[c, d] \\
g(y), y \in[d, e] \\
0, y \geq e .
\end{array}\right.
$$

Şekil 1'de sırasıyla $(3,6,8)$ üçgensel bulanık sayısının üyelik fonksiyonu ve $(1,5,7,8)$ yamuk bulanık sayısının üyelik fonksiyonu gösterilmiştir.
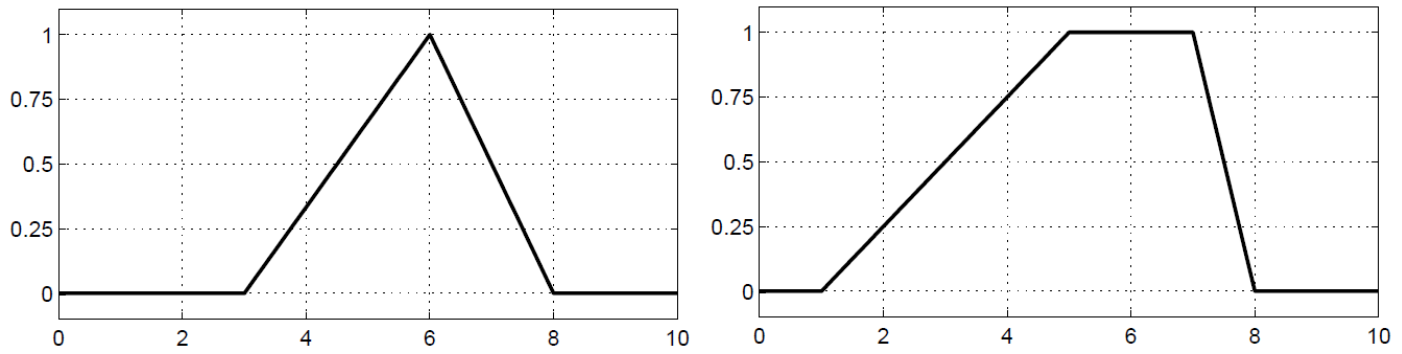

Şekil 1. Üyelik fonksiyonları.

Tanım 2: (Zadeh'in genişletme prensibi) $f: \mathbb{R}^{n} \rightarrow \mathbb{R}^{d}$ “crisp" fonksiyon, $\bar{f}$ karş1 gelen bulanık değerli fonksiyon ve $\bar{X}_{1}, \bar{X}_{2}, ., \bar{X}_{n}$ bulanık kümeler olsun. $\mathrm{O}$ zaman $\bar{Y}=\bar{f}\left(\bar{X}_{1}, \bar{X}_{2}, . ., \bar{X}_{n}\right)$ bulanık kümedir ve $\bar{Y}$ 'nin üyelik fonksiyonu aşağıdaki gibidir.

$v(y)=\left\{\begin{array}{c}\sup _{\left(x_{1}, x_{2}, \ldots, x_{n}\right) \in f^{-1}(y)} \min \left\{v_{1}\left(x_{1}\right), v_{2}\left(x_{2}\right), \ldots, v_{n}\left(x_{n}\right)\right\}, f^{-1}(y) \neq \varnothing \\ 0, f^{-1}(y)=\varnothing .\end{array}\right.$ 
[16]'da verilen Önerme 3, bulanık fonksiyonlarda yapılan işlemler ve dolayısıyla bulanık aritmetik için temel oluşturur.

Önerme 3: $f: \mathbb{R}^{n} \rightarrow \mathbb{R}^{d}$ sürekli fonksiyon, $d \leq n$ ve $\bar{X}_{1}, \bar{X}_{2}, ., \bar{X}_{n}$ bulanık sayılar olsun. Tanım 2'ye göre $\forall \alpha \in[0,1]$ için $Y^{\alpha}=f\left(X_{1}^{\alpha}, X_{2}^{\alpha}, . ., X_{n}^{\alpha}\right)$ olarak bulunur.

Sonuç 4: Her $i$ için $w_{i}$ nonnegatif skaler olmak üzere aşağıdaki bilgi geçerlidir. Kısa pozisyon sınırı varken portföy seçimi probleminde bunlar portföydeki $n$ adet varlığın ağırlıklarını gösterir.

$$
\sum_{i=1}^{n} w_{i}\left(b_{i}, c_{i}, e_{i}\right)=\left(\sum_{i=1}^{n} w_{i} b_{i}, \sum_{i=1}^{n} w_{i} c_{i}, \sum_{i=1}^{n} w_{i} e_{i}\right) .
$$

Tanım 5: $y$ belirsiz değişkeninin (rastgele değişken olmayabilir) olabilirlik dağılımı $\bar{Y}$ bulanık sayısı ile verilsin ve $B^{c}, B$ kümesinin tümleyeni olsun. O zaman "crisp" kümeler üzerinde olabilirlik ve gereklilik ölçüleri sırasıyla aşağıdaki gibi tanımlanır.

$$
\begin{aligned}
& P s(B):=\sup \{v(y): y \in B\}, \\
& N s(B):=1-P s\left(B^{c}\right) .
\end{aligned}
$$

$\mathrm{Bu}$ ölçüler ve olasılık ölçüsü $(\mathrm{P})$ arasındaki ilişki aşağıdaki gibidir. Buna göre Olabilirlik Teorisi kesin olmayan olasılık için alt ve üst sınırları belirler.

$$
N s(B) \leq P(B) \leq P s(B) .
$$

(5) ve (6)'ya göre aşağıdaki bilgi geçerlidir. Buna göre y sürekli rastgele değişkeninin olasılık ve olabilirlik dağılımlarının destekleri özdeştir ve $Y^{0}$ 'a eşittir.

$$
1-\alpha=N s\left(Y^{\alpha}\right) \leq P\left(Y^{\alpha}\right) \leq P s\left(Y^{\alpha}\right)=1
$$

\section{Olabilirlik ortalama - varyans modelinin teorisi}

Bu bölümde olabilirlik OV modeli ile ilgili temel kavramlar verildikten sonra fayday1 ya da performansı maksimum yapan portföyler analitik olarak elde edilmiştir.

Tanım 6 ([10, 17]): Belirsiz değişken y'nin olabilirlik dağılımı $\bar{Y}$ bulanık sayısı ile verilsin. $Y^{\alpha}=\left[Y_{L}(\alpha), Y_{R}(\alpha)\right], \forall \alpha \in[0,1]$ olmak üzere $y^{\prime}$ nin olabilirlik ortalaması ve varyansı aşağıdaki gibi tanımlanır. 


$$
\begin{aligned}
& E_{p}(y):=\int_{0}^{1} \alpha\left(Y_{R}(\alpha)+Y_{L}(\alpha)\right) d \alpha, \\
& \operatorname{Var}_{p}(y):=0.5 \int_{0}^{1} \alpha\left(Y_{R}(\alpha)-Y_{L}(\alpha)\right)^{2} d \alpha .
\end{aligned}
$$

Önerme $7([10,11,17])$ : Getirilerin rastgele vektörü $r$ ile portföyün ağırlık vektörü $w$ ile gösterilsin. Her $i$ için $r_{i}$ rastgele değişkeninin olabilirlik dağılımı $\left(b_{i}, c_{i}, e_{i}\right)$ olsun. Zadeh'in genişletme prensibine ve Tanım 6'ya göre aşağıdaki eşitlikler geçerlidir.

$$
\begin{aligned}
& E_{p}\left(w^{T} r\right)=\sum_{i=1}^{n} w_{i} E_{p}\left(r_{i}\right)=\sum_{i=1}^{n} w_{i} \mu_{i}=\sum_{i=1}^{n} w_{i}\left(\frac{b_{i}+4 c_{i}+e_{i}}{6}\right), \\
& \operatorname{Var}_{p}\left(w^{T} r\right)=\left(\sum_{i=1}^{n}\left|w_{i}\right| \sqrt{\operatorname{Var}_{p}\left(r_{i}\right)}\right)^{2}=\left(\sum_{i=1}^{n}\left|w_{i}\right| \sigma_{i}\right)^{2}=\left(\sum_{i=1}^{n}\left|w_{i}\right|\left(\frac{e_{i}-b_{i}}{2 \sqrt{6}}\right)\right)^{2} .
\end{aligned}
$$

Uyarı: Portföy getirisinin olabilirlik dağılımı, bulanık aritmetik ile bulunur. Özel olarak kısa pozisyon sınırı varken (4)'teki bilgiler geçerlidir. $\mathrm{Bu}$ olabilirlik dağılımının, olabilirlik ortalaması ve varyansı doğrudan Tanım 6 kullanılarak bulunduğunda da (9) ile özdeş sonuçlar elde edilir.

Varlık getirilerinin ${ }^{\dagger}$ olabilirlik dağılımlarının belirlenmesinde standart bir yöntem yoktur. Bunlar geçmiş getiriler ve/veya kişisel yargılar ve beklentiler doğrultusunda belirlenebilir. Örneğin [11]'de sırasıyla geçmiş getirilerin minimumu, ortalaması ve maksimumu kullanılarak belirlenmiştir. Kişisel yargılar ve beklentiler doğrultusunda, bu tanımlayıcı istatistiklerden elde edilen değerler artırılabilir veya azaltılabilir.

Uygun çözüm kümesi (S) konveks ve kapalı olmak üzere olabilirlik OV modeli aşağıdaki çok amaçlı konkav maksimizasyon problemi ile verilebilir.

$$
\sup _{w \in S}\left(E_{p}\left(w^{T} r\right)\right) \wedge\left(-\operatorname{Var}_{p}\left(w^{T} r\right)\right) .
$$

Çok amaçlı konkav maksimizasyon problemleri için ağırlıklı amaç metodu etkin sınırı tam olarak verir [18]. Bu nedenle (10) ve (11) problemlerinin etkin sınırları özdeştir. (11)'de ilk amacın ağırlığı olan $\beta,[0,1]$ arasında değişmektedir.

$$
\sup _{w \in S} \beta\left(\sum_{i=1}^{n} w_{i} \mu_{i}\right)+(1-\beta)\left(-\left(\sum_{i=1}^{n}\left|w_{i}\right| \sigma_{i}\right)\right)
$$

Uyarı: Önerme 7'ye göre aşağıdaki bilgi geçerlidir. Buna göre olabilirlik ortalaması ve standart sapması zamanın lineer fonksiyonudur. Bu nedenle olabilirlik OV modelinin sonucu, Markovitz'in geleneksel OV modelinde olduğu gibi elde tutma periyodunun süresinden $(\mathrm{t})$ bağımsızdır.

\footnotetext{
${ }^{\dagger}$ Elde tutma periyodu için ek (risksiz faiz oranı üzerindeki) logaritmik getiriler.
} 


$$
\begin{aligned}
& E_{p}\left(\sum_{j=1}^{t} r_{i, j}\right)=t \mu_{i}, \\
& \operatorname{Var}_{p}\left(\sum_{j=1}^{t} r_{i, j}\right)=t^{2} \sigma_{i}^{2} .
\end{aligned}
$$

Önerme 7'e göre tüm varlıkların arasındaki olabilirlik korelasyonu 1'dir. Hatta A varlığının uzun pozisyonu ile B varlığının hem uzun pozisyonu hem de kısa pozisyonu arasındaki olabilirlik korelasyonları 1'dir. Ayrıca olabilirlik dağılımlarından bağımsız olarak olabilirlik korelasyonları her zaman için nonnegatiftir [17]. Bu nedenle bu model ile ilgili aşağıdaki bilgiler verilebilir.

- Yalnızca kısa pozisyon sınırı varken finansal olarak anlamlı sonuç verir.

- Markovitz'in geleneksel OV modelindeki durumun aksine portföyü çeşitlendirme yaklaşımı risk azaltmada kullanılamaz.

[1]'de olduğu gibi portföyde kısa pozisyon ve risksiz varlık bulunamasın. Buna göre $S$ aşağıdaki gibidir.

$$
S=\left\{w: \sum_{i=1}^{n} w_{i}=1 \wedge w_{i} \geq 0, \forall i\right\} .
$$

Ayrıca (11) aşağıdaki lineer maksimizasyon problemine indirgenir.

$$
\sup \left\{\sum_{i=1}^{n} w_{i}\left(\beta \mu_{i}+(\beta-1) \sigma_{i}\right): \sum_{i=1}^{n} w_{i}=1 \wedge w_{i} \geq 0, \forall i\right\}
$$

Portföyün toplamsal fayda fonksiyonu, $i$. varlığın faydası $\theta_{i}:=\left(\beta \mu_{i}+(\beta-1) \sigma_{i}\right)$ olmak üzere aşağıdaki gibidir.

$$
\sum_{i=1}^{n} w_{i} \theta_{i}
$$

Anlatım kolaylığını sağlamak amacıyla bu çalışmada aşağıdaki varsayımlar yapılmıştır.

- V1: En az bir varlığın olabilirlik ortalaması pozitiftir.

- V2: Olabilirlik ortalamasını ve standart sapmasını eniyileyen portföyler tektir.

- V3: Varlıkların olabilirlik standart sapması - olabilirlik ortalaması düzlemindeki koordinatları birbirlerinden farklıdır. Aksi halde ilgili varlıklar tek bir varlık olarak düşünülebilir.

V2 geçerli iken herhangi bir $\beta$ değeri için (14)'ün optimal çözümü etkin portföy olarak adlandırılır. Etkin portföy, verilen olabilirlik standart sapması için olabilirlik ortalamasını maksimum yapan portföy olarak da tanımlanabilir. Bunlar birlikte olabilirlik standart sapması - olabilirlik ortalaması düzleminde etkin sınırı verir. Köşe Noktası Teoremine göre bunlarla ilgili aşağıdaki bilgiler geçerlidir. 
- Verilen $\beta$ değeri için tek bir varlığın faydası maksimum ise etkin portföy tektir. $\mathrm{Bu}$ portföyde yalnızca o varlık bulunur.

- Eğer iki veya daha fazla varlığın faydası maksimum ise bu varlıkların herhangi bir konveks kombinasyonu etkin portföydür.

Performans, birim olabilirlik standart sapması başına olabilirlik ortalaması olarak tanımlansın. Bunu maksimum yapan portföy aşağıdaki lineer kesirli programla problemi ile bulunur. Bu portföy, V1 geçerli iken tanımı gereği etkin portföydür ve (olabilirlik) piyasa portföyü olarak adlandırılabilir.

$\sup \left\{\frac{\sum_{i=1}^{n} w_{i} \mu_{i}}{\sum_{i=1}^{n} w_{i} \sigma_{i}}: \sum_{i=1}^{n} w_{i}=1 \wedge w_{i} \geq 0, \forall i\right\}$.

(16) lineer programlama problemine indirgenip Simpleks algoritma ile çözülebilir [19]. Ayrıca kuasikonveks problemdir ve bu nedenle bu problemin en az bir çözümü uygun çözüm kümesinin köşelerindedir [20]. Bununla birlikte aşağıdaki bilgilerin geçerli olduğu da gösterilebilir [21].

- Tek bir varlığın performansı maksimum ise piyasa portföyü tektir. Bu portföyde yalnızca o varlık bulunur.

- Eğer iki veya daha fazla varlığın performansı maksimum ise bu varlıkların herhangi bir konveks kombinasyonu piyasa portföyüdür.

Bazı özel durumlar için etkin portföyleri incelemek yararlı olabilir.

i. Varlık ağırlıkları için $m<n$ olmak üzere üst sınır getirilsin ve $S$ aşağıdaki gibi olsun.

$$
S=\left\{w:\left(\sum_{i=1}^{n} w_{i}=1\right) \wedge\left(\frac{1}{m} \geq w_{i} \geq 0, \forall i\right)\right\} .
$$

$\mathrm{Bu}$ durumda fayda (performans) siralamasinda $m$. ve $(m+1)$. olan varlıkların faydasi (performans1) farklı ise etkin portföy (piyasa portföyü) tektir. Bu portföyde faydas1 (performansı) maksimum olan $m$ adet varlık eşit ağırlıklı olarak bulunur.

ii. Portföyde risksiz varlık bulunabilsin ama kısa pozisyon bulunamasın. Buna göre $S$ aşağıdaki gibidir. Burada risksiz varlığın ağırlığı ile riskli varlıkların ağırlıklarının toplamı 1'dir.

$$
S=\left\{w:\left(\sum_{i=1}^{n} w_{i} \leq 1\right) \wedge\left(w_{i} \geq 0, \forall i\right)\right\} .
$$

$\mathrm{Bu}$ durumda performansı maksimum yapan portföy, piyasa portföyü ile risksiz varlığın herhangi bir konveks fonksiyonudur. Sadece bu portföyler etkin portföylerdir ve birlikte etkin sınırı oluşturur. Buna göre Markovitz'in geleneksel OV modelinde olduğu gibi burada da Tek Fon Teoremi geçerlidir. V1 nedeniyle pozitif olan piyasa portföyünün performansı $p$ ile gösterilsin. Faydayı maksimum yapan etkin portföy 
aşağıdaki $\beta^{o}$ değerine kadar sadece risksiz varlık iken bu değerden sonra sadece piyasa portföyüdür. $\mathrm{Bu} \beta^{0}$ değerinde ise bunların herhangi bir konveks kombinasyonudur. Başka bir deyişle bu $\beta^{0}$ için tüm etkin sınır faydayı maksimum yapar.

$\beta^{0}=\frac{1}{1+p}$

iii. Portföyde risksiz varlık bulunamasın ama kısa pozisyon bulunabilsin. Buna göre $S$ aşağıdaki gibidir.

$$
S=\left\{w: \sum_{i=1}^{n} w_{i}=1\right\}
$$

Bu durumda olabilirlik OV modeli ya kısa pozisyon sınırı varmış gibi sonuç verir ya da sınırlı tek bir çözüm bulunamaz. Bu bilgi kısa pozisyon sınırı yokken modelin finansal olarak anlamlı olmaması ile uyumludur.

\section{Olabilirlik ortalama - varyans modelinin etkin sınırı}

Etkin portföyler, olabilirlik standart sapması - olabilirlik ortalaması düzleminde etkin sınırı verir. Bu bölümde kısa pozisyon sınırı varken, farklı etkin sınır yapıları örnekler ile açıklanmıştır.

(21) olabilirlik OV modelinin alternatif tanımıdır ve (14) ile özdeş etkin sınır verir. (14)'te fayda maksimizasyonu söz konusu iken burada olabilirlik standart sapmasının verilen üst sınırı için olabilirlik ortalaması maksimize edilir.

$$
\begin{gathered}
\text { maks } \sum_{i=1}^{n} w_{i} \mu_{i} \\
\text { s.t. } \sum_{i=1}^{n} w_{i} \sigma_{i} \leq \sigma_{\text {isst }} \\
\sum_{i=1}^{n} w_{i}=1 \\
w_{i} \geq 0, \forall i .
\end{gathered}
$$

Simpleks algoritmadan bilindiği üzere optimal çözüm dejenere değilse veya alternatif optimal çözümler yoksa (21)'in optimal çözümünde tam olarak iki varlık bulunur. (14) ve (21) birlikte dikkate alındığında etkin sınır için aşağıdaki bilgiler verilebilir.

- V1 ve V2 geçerli olsun. Ayrıca olabilirlik ortalamasını ve standart sapmasını eniyileyen portföyler aynı olsun. Buna göre etkin sınır tek bir noktadan oluşur. Bu nokta tek bir varlıktan oluşan piyasa portföyüdür.

- Aksi halde bir veya daha fazla doğru parçasından oluşan konkav bir eğridir. V3 geçerli iken doğru parçalarının uç noktaları, birer varlığa karşı gelir. Bu noktalar 
(21)'in dejenere çözümleridir. Uç olmayan noktalar ise doğru parçasının iki uç noktasının bir konveks kombinasyonu ile elde edilir.

- Eğer bir doğru parçası üzerinde üç veya daha fazla varlık varsa alternatif optimal çözümler vardır. Buna göre o doğru parçası üzerindeki uç olmayan herhangi bir nokta, bu varlıkların sonsuz farklı sayıda konveks kombinasyonu ile elde edilebilir.

- Tüm varlıklar ilgili düzlemde nokta şeklinde gösterilsin. Etkin sınır üzerinde olmayan noktalar etkin portföy değildir. Bunlar grafikte etkin sınırın altında ve sağında kalır. $\mathrm{Bu}$ varlıkları içeren herhangi bir portföy de etkin değildir. Rasyonel bir yatırımcının bu portföylere yatırım yapmaması beklenir.

(14)'te $\beta$ belirli aralıklarda iken uç noktalar elde edilir. İki uç noktanın faydasının bir $\beta^{o}$ için eşit olduğu yerlerde ise aralık değişimleri gerçekleşir. İlgili doğru parçasının eğimi $e$ iken $\beta^{o}$ aşağıdaki gibi bulunur. Etkin sınır konkav eğri olduğundan bunu oluşturan doğru parçalarının eğimleri gittikçe azalır. Bu nedenle $\beta^{o}$ değerleri de gittikçe artar.

$\beta^{0}=\frac{1}{1+e}$

Uyarı: Portföyde risksiz varlık bulunabiliyorken (19)'daki $p$ ile (22)'deki $e$ özdeştir. Çünkü risksiz varlığın olabilirlik ortalaması ve varyansı sıfırdır ve etkin sınır bu örnekte piyasa portföyü ile risksiz varlığı birleştiren doğru parçasıdır.

Örnek I ve II'de A, B, C, D ve E varlıkları için aşağıdaki bilgiler geçerli olsun. Örnek II'nin, Örnek I'den tek farkı A varlığının olabilirlik standart sapmasıdır.

Tablo 1. Etkin sınır örnekleri için veriler I.

\begin{tabular}{|c|c|c|c|c|}
\hline & \multicolumn{2}{|c|}{ Örnek I } & \multicolumn{2}{c|}{ Örnek II } \\
\hline Varlıklar & O. Ortalamas1 & O. Standart S. & O. Ortalamas1 & O. Standart S. \\
\hline A & -0.05 & 0.15 & -0.05 & 0.05 \\
\hline B & 0.10 & 0.15 & 0.10 & 0.15 \\
\hline C & 0.15 & 0.10 & 0.15 & 0.10 \\
\hline D & 0.05 & 0.20 & 0.05 & 0.20 \\
\hline E & 0.05 & 0.15 & 0.05 & 0.15 \\
\hline
\end{tabular}

Örnek I'de C varlığı olabilirlik ortalamasını ve standart sapmasını eniyiler. Bu nedenle burada etkin sınır sadece C varlığından oluşur. Örnek II'de sadece A ve C varlıkları etkin portföylerdir. Bu nedenle etkin sinır, A ve C'nin konveks kombinasyonları ile oluşturulan ve eğimi 4 olan bir doğru parçasıdır. (22)'ye göre etkin portföyler; $\beta<0.2$ iken sadece $\mathrm{A}$ varlığından, $\beta>0.2$ iken sadece $\mathrm{C}$ varlığından oluşur. $\beta=0.2$ ise tüm bir etkin sınır faydayı maksimum yapar. Başka bir deyişle (14)'ün alternatif optimal çözümleri vardır. Örnek I ve II'de C varlığı performansı maksimum yapar ve piyasa portföyüdür. Örnek I ve II için etkin sınırlar Şekil 2'de sırasıyla gösterilmiştir. 

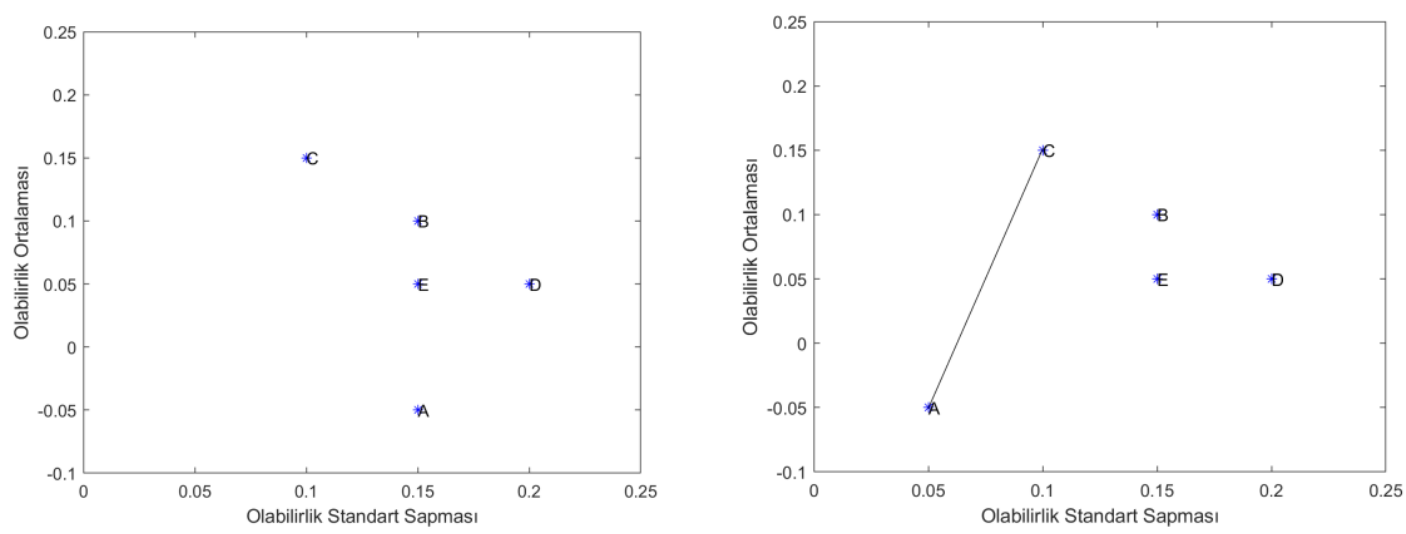

Şekil 2. Etkin sınırlar I.

Örnek III ve IV'te A, B, C, D ve E varlıkları için aşağıdaki bilgiler geçerli olsun. Örnek III ve IV'ün, Örnek II'den tek farkı B varlığının olabilirlik ortalamasıdır.

Tablo 2. Etkin sınır örnekleri için veriler II.

\begin{tabular}{|c|c|c|c|c|}
\hline & \multicolumn{2}{|c|}{ Örnek III } & \multicolumn{2}{c|}{ Örnek IV } \\
\hline Varlıklar & O. Ortalamas1 & O. Standart S. & O. Ortalamas1 & O. Standart S. \\
\hline A & -0.05 & 0.05 & -0.05 & 0.05 \\
\hline B & 0.20 & 0.15 & 0.35 & 0.15 \\
\hline C & 0.15 & 0.10 & 0.15 & 0.10 \\
\hline D & 0.05 & 0.20 & 0.05 & 0.20 \\
\hline E & 0.05 & 0.15 & 0.05 & 0.15 \\
\hline
\end{tabular}

Örnek III'te A, B ve C varlıkları etkin portföylerdir. Buradaki etkin sınır, iki doğru parçasını uç uca ekleyerek oluşturulan konkav eğridir. Etkin portföyler; $\beta<0.2$ iken sadece $\mathrm{A}$ varlığından, $0.2<\beta<0.5$ iken sadece $\mathrm{C}$ varlığından, $\beta>0.5$ iken sadece $\mathrm{B}$ varlığından oluşur. $\beta=0.2$ iken ( $\beta=0.5$ iken) $A$ ve $C$ 'nin ( $C$ ve $B$ 'nin) herhangi bir konveks kombinasyonu faydayı maksimum yapar ve etkin portföydür. Burada piyasa portföyü yine C'dir. Örnek III ve IV için etkin sınırlar Şekil 3 'te sırasıyla gösterilmiştir.
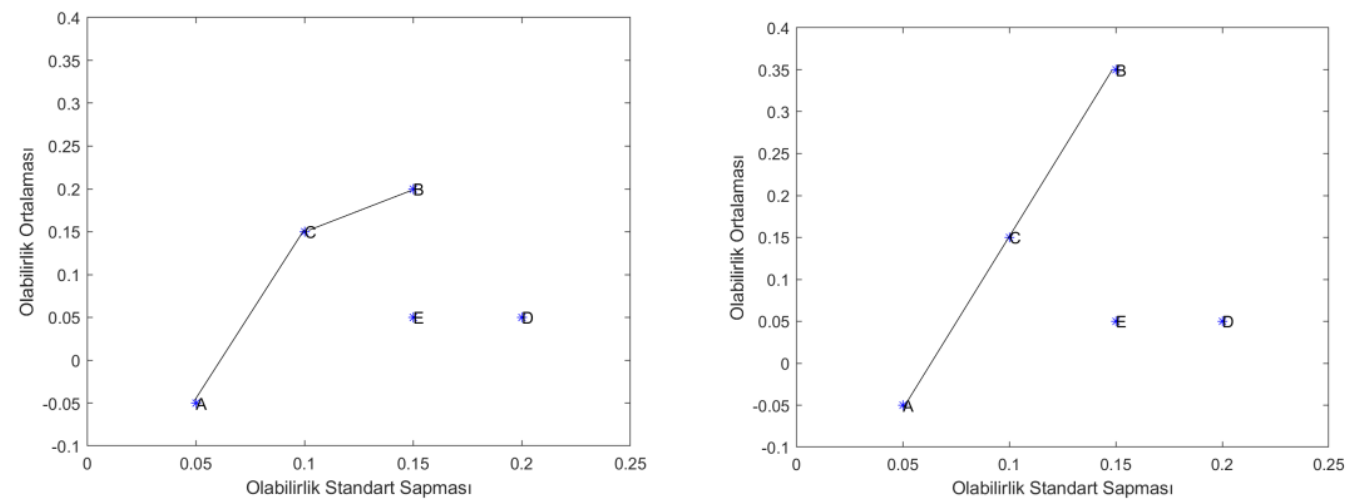

Şekil 3. Etkin sınırlar II.

Örnek IV'te etkin sınırı oluşturan iki doğru parçasının eğimi aynı olduğundan etkin sınır doğrusaldır ve piyasa portföyü sadece $\mathrm{B}$ varlığından oluşur. Etkin portföyler; $\beta<0.2$ iken sadece $\mathrm{A}$ varlığından, $\beta>0.2$ iken sadece $\mathrm{B}$ varlığından oluşur. $\beta=0.2$ ise $\mathrm{A}, \mathrm{B}$ ve 
C'nin herhangi bir konveks kombinasyonu faydayı maksimum yapar ve etkin portföydür. Ayrıca (21)'de $0.05<\sigma_{u ̈ s t}<0.15$ iken alternatif optimal çözümler vardır ve karşı gelen etkin portföyler A, B ve C'nin sonsuz farklı sayıda konveks kombinasyonu ile elde edilebilir. Örneğin, $(0.10,0.15)$ koordinatlarındaki bir etkin portföy $\mathrm{C}$ varlığ 1 ve $(0.5 \mathrm{~A}+0.5 \mathrm{~B})$ portföyünün herhangi bir konveks kombinasyonu ile oluşturulabilir.

\section{Sonuç ve değerlendirme}

Varlık getirilerinin olasılık dağılımlarını tam olarak belirlemek çoğu zaman mümkün olmayabilir. Bu nedenle yapılan normal dağılım veya eliptik dağılım varsayımları ise gerçek hayattaki durumla örtüşmeyebilir. Öte yandan bunların en kötü durumdaki, temel durumdaki ve en iyi durumdaki değerleri için öngörüde bulunmak nispeten daha kolaydır. $\mathrm{Bu}$ öngörüler doğrultusunda ise varlık getirilerinin olabilirlik dağılımları üçgensel bulanık sayılarla verilebilir. $\mathrm{Bu}$ çalışmada bu bilgiler doğrultusunda Olabilirlik OV modelinin matematiksel analizi yapılmıştır. Bu kapsamda faydayı ya da performansı maksimum yapan portföyler, analitik olarak elde edilmiştir. Ayrıca farklı etkin sınır yapıları örnekler ile açıklanmıştır. Elde edilen bu sonuçların, bu modelle yapılacak uygulamaları ve karar almayı kolaylaştırması beklenmektedir.

\section{Kaynaklar}

[1] Markowitz, H., Portfolio selection, The Journal of Finance, 7, 1, 77-91, (1952).

[2] Goldfarb, D. ve Iyengar, G., Robust portfolio selection problems, Mathematics of Operations Research, 28, 1, 1-38, (2003).

[3] Breuer, T., Providing against the worst: risk capital for worst case scenarios, Managerial Finance, 32, 9, 716-730, (2006).

[4] Garlappi, L., Uppal, R. ve Wang, T., Portfolio selection with parameter and model uncertainty: A multi-prior approach, The Review of Financial Studies, 20, 1, 41-81, (2006).

[5] Tütüncü, R. H. ve Koenig, M., Robust asset allocation, Annals of Operations Research, 132, 1-4, 157-187, (2004).

[6] Huang, D., Zhu, S., Fabozzi, F. J. ve Fukushima, M., Portfolio selection under distributional uncertainty: a relative robust CVaR approach, European Journal of Operational Research, 203, 1, 185-194, (2010).

[7] Bhattacharyya, R., Kar, S. ve Majumder, D. D., Fuzzy mean-variance-skewness portfolio selection models by interval analysis, Computers \& Mathematics with Applications, 61, 1, 126-137, (2011).

[8] Duran, A. ve Bommarito, M. J., A profitable trading and risk management strategy despite transaction costs, Quantitative Finance, 11, 6, 829-848, (2011).

[9] Jorion, P., Bayes-Stein estimation for portfolio analysis, The Journal of Financial and Quantitative Analysis, 21, 3, 279-292, (1986).

[10] Carlsson, C., Fullér, R. ve Majlender, P., A possibilistic approach to selecting portfolios with highest utility score, Fuzzy Sets and Systems, 131, 1, 13-21, (2002).

[11] Taş, O., Kahraman, C. ve Güran, C. B., A Scenario Based Linear Fuzzy Approach in Portfolio Selection Problem: Application in the Istanbul Stock Exchange, Journal of Multiple-Valued Logic \& Soft Computing, 26, 3-5, 269-294, (2016). 
[12] Zhang, W. G., Zhang, X. L. ve Xiao, W. L., Portfolio selection under possibilistic mean-variance utility and a SMO algorithm, European Journal of Operational Research, 197, 2, 693-700, (2009).

[13] Dubois, D., Possibility theory and statistical reasoning, Computational Statistics \& Data Analysis, 51, 1, 47-69, (2006).

[14] Klir, G. ve Yuan, B., Fuzzy sets and fuzzy logic, Prentice Hall, (1995).

[15] Zimmermann, H. J., Fuzzy set theory and its applications, Springer, (2001).

[16] Roman-Flores, H., Barros, L. C. ve Bassanezi, R. C., A note on Zadeh's extensions, Fuzzy Sets and Systems, 117, 3, 327-331, (2001).

[17] Carlsson, C. ve Fuller, R., On possibilistic mean value and variance of fuzzy numbers, Fuzzy Sets and Systems, 122, 315-326, (2001).

[18] Deb, K., Multi-objective optimization using evolutionary algorithms, John Wiley \& Sons, (2001).

[19] Bajalinov, E. B., Linear-fractional programming theory, methods, applications and software, Springer, (2013).

[20] Bykadorov, I. A., On quasiconvexity in fractional programming in Komlosi, S., Rapcsak, T. ve Schaible, S., Generalized Convexity, Springer, (1994).

[21] Biswas, A., Verma, S., ve Ojha, D. B., Optimality and Convexity Theorems for Linear Fractional Programming Problem, International Journal of Computational and Applied Mathematics, 12, 3, 911-916, (2017). 